\title{
Inflammatory response associated with choke vessel remodeling in the extended perforator flap model
}

\author{
LIMING QING* , PENGFEI LEI* , JUYU TANG, PANGFENG WU, LONG WANG, JIE XIE and YIHE HU \\ Department of Orthopaedics, Xiangya Hospital of Central South University, Changsha, Hunan 410008, P.R. China
}

Received January 6, 2016; Accepted December 23, 2016

DOI: $10.3892 /$ etm.2017.4205

\begin{abstract}
Ischemic necrosis of the surgical flap is a common complication. The behavior of choke vessels has an important role in skin flap survival. However, the mechanism of choke vessel remodeling has remained elusive. The purpose of the present study was to investigate the possible association between inflammatory responses and choke vessel remodeling in the extended perforator flap model in rats. After flap elevation, the animals were randomly divided into three groups ( $n=6$ in each) for tissue analysis at three, five or seven days after flap surgery. Six additional rats served as a control group (no flap elevation). Tissue samples were collected from the choke zone for histological, western blot and PCR analyses. Monocyte chemoattractant protein-1 (MCP-1) and tumor necrosis factor- $\alpha$ (TNF- $\alpha$ ) as inflammatory cytokines were examined in the present study. Histopathological analysis showed that dilation of choke vessels and increased vessel wall thickness was obvious after flap elevation. It also showed edema, inflammation cell aggregation after the operation. Compared with the control group, the protein and mRNA expression levels of MCP-1 and TNF- $\alpha$ were significantly increased at days 3,5 and 7 after flap elevation, while reaching a maximum at day 5 . These findings indicated that inflammatory responses may have an important role in choke vessel remodeling. MCP-1 and TNF- $\alpha$ may be considered as potential targets for modulating the behavior of choke vessels.
\end{abstract}

\section{Introduction}

Perforator flaps are in frequent use in reconstructive and plastic surgery to cover soft-tissue defects caused by tumor ablation or trauma $(1,2)$. However, due to critical disruption of the blood

Correspondence to: Professor Yihe Hu, Department of Orthopaedics, Xiangya Hospital of Central South University, 87 Xiangya Road, Changsha, Hunan 410008, P.R. China

E-mail: csuhuyihe@163.com

*Contributed equally

Key words: perforator flap, choke vessels, biomarkers, inflammation supply, flaps often present with partial necrosis (3). Choke vessels have an important role in skin flap survival $(4,5)$. They are part of the venous as well as arterial skin circulation, and under normal physiological conditions, they are small-caliber vessels extending between the tips of the branches of adjacent vascular trees (6). An angiographic study reported that the difference in the survival area of flaps is attributable to the behavior of the choke zone (7). One perforator vessel can safely perfuse an adjacent territory via dilation of a choke vessel. According to a detailed study on choke vessels by Zhuang et al (8), the diameter of choke vessels increased at 3 days after flap elevation and further increased to reach a maximum at day 5. Subsequent to flap elevation, their tortuosity increased as well, leading to increased vascular length, with the greatest change occurring from day 5 until day 7 . However, the underlying mechanisms of choke vessel dilation remain elusive.

Dhar and Taylor (9) postulated that the physical effects of blood flow and hypoxia are two major factors that result in choke vessel dilation. Miyamoto et al (7) also suggested that flow-mediated dilation is a factor contributing to the dilation of choke vessels. If a flap is transferred with anastomosis to a recipient artery with higher blood flow, shear stress even showed sufficient increases to dilate the second choke vessels in an extended flap. Of note, in heart disorders and limb ischemic models, the important role of the inflammatory response has been extensively illustrated with regard to its association with hypoxia-dependent as well as mechanical stress-dependent vessel growth (10-12). The present study therefore hypothesized that the inflammatory response was associated with choke vessel changes in the extended perforator flap.

Inflammatory responses contribute to vascular remodeling during tissue repair or ischemia $(13,14)$. Several studies have linked mechanical stress with production of various pro-inflammatory molecules, such as interleukin (IL)-8, IL-6, monocyte chemoattractant protein-1 (MCP-1) and tumor necrosis factor- $\alpha$ (TNF- $\alpha)(15,16)$. Of these, MCP-1 and TNF- $\alpha$ are widely recognized as major components of chronic inflammation associated with a variety of ischemic events $(17,18)$. Chemokines are potent mediators of cell migration and adhesion via interacting with a family of G-protein-coupled receptors expressed on leukocytes. MCP-1 is most extensively studied chemokine contributing to neovascularization. Numerous studies have demonstrated the marked enhancement of MCP-1 at sites of collateral growth $(19,20)$. 
TNF- $\alpha$ is cytokine with multiple functions, which regulates diverse physiological and pathophysiological events, including cell growth, differentiation, angiogenesis, survival, apoptosis and inflammation (21). Therefore, MCP-1 and TNF- $\alpha$ have been evaluated as inflammatory markers to evidence inflammatory responses.

The purpose of the present study was to investigate the possible association between inflammatory responses and choke vessel remodeling in the extended perforator flap model. The inflammatory markers MCP-1 and TNF- $\alpha$ were also investigated in order to elucidate the underlying molecular events in this process.

\section{Materials and methods}

Animals. A total of 24 male Sprague-Dawley rats (Department of Laboratory Animals, Central South University, Changsha, China, 10 weeks old, weight 250-300 g) were used in the present study. The rats were housed in the Animal Care Center of Xiangya Hospital of Central South of University and provided with free access to food and water. Rats were kept at a regulated temperature $\left(21 \pm 3^{\circ} \mathrm{C}\right)$ and humidity $(55 \pm 5 \%)$, and a 12-h light/dark cycle. All manipulations and surgical procedures were performed in accordance with the guidelines of the China Council of Animal Care and with approval of the Central South University Committee on Laboratory Animals. The animal protocol was reviewed and approved by the Ethical Committee of XiangYa School of Medicine, Central South University. Following flap elevation, the animals were randomly divided into three groups ( $n=6$ in each group) for tissue analysis at three, five or seven days after flap surgery. Six additional rats served as a control group (no flap elevation).

Flap design. In the present study, an extended dorsal skin perforator flap model was used. The perforator flap was marked on the dorsolateral side. Based on previous studies and an angiographic study by our group (8), this flap contains two even vascular territories, the iliolumbar artery perforator vessel and the posterior interior intercostal artery perforator vessel. The size of the flap was $\sim 3 \times 8 \mathrm{~cm}$ (Fig. 1).

Flap elevation. All animals were anesthetized with pentobarbital sodium $(30 \mathrm{mg} / \mathrm{kg}$, intraperitoneal; Sigma-Aldrich; Merck Millipore, Darmstadt, Germany). Fur was shaved from the dorsal surface and the skin was washed with hibitane, $75 \%$ alcohol and iodine Shandong Ruitai Odd Washing Disinfection Technology Co., Ltd., Shandong, China). The flap was outlined with a felt-tipped surgical marker. Flap elevation was started with an incision at the medial border. The periphery of the flap was incised and hemostasis was achieved. The surgical flap was then raised by sharp dissection in the plane between the panniculus carnosus and the deep fascia and the two blood vessels of interest were confirmed. Cutaneous blood vessels were cauterized as they were encountered, except for the planned perforator pedicle. The posterior intercostal artery perforator was ligated and severed, creating an island flap that relied solely on the iliolumbar artery perforator for its blood supply. After flap elevation, the anastomotic line between the iliolumbar artery perforator and the posterior intercostal artery perforator (choke vessel zone) was marked on the flap's surface (Fig. 2). The flap was then replaced at the surgical site and secured with 4-0 monofilament sutures and wound clips. Following anesthetic recovery, the rats were placed in a clean cage. Animals were monitored daily for signs of dehiscence and self-mutilation.

Angiography. To visualize vascular networks in the skin flap, following exsanguination, one control rat and one rat were injected with gelatin/lead oxide seven days after flap surgery, following the method described by Zhuang et al (8). In brief, $5 \mathrm{~g}$ gelatin was diluted in $100 \mathrm{ml}$ tap water, heated to $40^{\circ} \mathrm{C}$ and followed by the addition of $100 \mathrm{mg}$ water-soluble red lead oxide $\left(\mathrm{Pb}_{3} \mathrm{O}_{4}\right.$, Jining Hengtai Chemical Co., Ltd., Jining, China). This mixture was injected into the rat's carotid artery until the rat's limbs turned red. After injection, the integument was carefully dissected in the plane between the panniculus carnosus and the deep fascia. The integument was then fixed for $24 \mathrm{~h}$ at $4^{\circ} \mathrm{C}$. The flaps were obtained and radiographed $(55 \mathrm{kVp}, 25 \mathrm{~mA}$, $20 \mathrm{sec}$ exposure) with a soft X-ray machine (Fuji Computerized Radiography XG-1; Fujifilm, Tokyo, Japan).

Histological analysis. A sample from the first choke zone was excised and stored in $4.5 \%$ buffered formaldehyde solution. Formaldehyde-fixed samples were processed in paraffin and stained with hematoxylin/eosin using standard histology protocols. Samples were examined for infiltration of polymorphonuclear leukocytes, inflammatory cells and interstitial edema.

Western blot analysis. Tissue samples were harvested from the first choke zones. These samples were homogenized in lysis buffercontaining $20 \mathrm{mmol} / \mathrm{l}$ Tris- $\mathrm{HCl}, \mathrm{pH} 7.4,150 \mathrm{mmol} / \mathrm{lNaCl}$, $1 \mathrm{mmol} / \mathrm{l}$ EDTA, $1 \mathrm{mmol} / 1$ EGTA, $1 \%$ Triton X-100, $2.5 \mathrm{mmol} / 1$ sodium orthovanadate, $1 \mu \mathrm{g} / \mathrm{ml}$ leupeptin and $1 \mathrm{mmol} / 1$ phenylmethyl sulfonyl fluoride. The samples were centrifuged to pellet the debris and the supernatants were analyzed using Bradford protein assay (Bio-Rad Laboratories, Inc., Hercules, CA, USA). A volume of each extract corresponding to $25 \mu \mathrm{g}$ of total protein was resolved on $10 \%$ sodium dodecyl sulfate-polyacrylamide gels and electrotransferred to polyvinylidene difluoride membranes (Bio-Rad Laboratories, Inc.). The membranes were blocked in phosphate-buffered saline with $0.1 \%$ Tween-20 (PBS-T) containing 5\% milk powder for $30 \mathrm{~min}$ at room temperature and then incubated overnight at $4^{\circ} \mathrm{C}$ with one of the following primary antibodies: Anti-TNF- $\alpha$ antibody (sc-1349, Santa Cruz Biotechnology, Inc., Dallas, TX, USA) at a dilution of 1:1,000, anti-MCP-1 antibody (sc-1785, Santa Cruz Biotechnology, Inc.) at a dilution of 1:1,000 and anti- $\beta$-actin polyclonal antibody (A5441, Sigma-Aldrich; Merck Millipore) at a dilution of 1:1,000 as a loading control. The membranes were subsequently incubated with horseradish peroxidase-conjugated anti-mouse immunoglobulin G (1:1,000; sc-2748, Santa Cruz Biotechnology, Inc.) for $2 \mathrm{~h}$ at room temperature. Immunoreactivity signals were visualized by 3,3'-Diaminobenzidine tetrahydrochloride (AR1000; Wuhan Boster Biological Technology, Ltd., Wuhan, China) and a Tocan 240 Tanon Gel Imaging System (Tanon Science \& Technology Co., Ltd., Shanghai, China) and analyzed using Image-Pro plus Software 6.0 (Media Cybernetics, Rockville, MD, USA). 

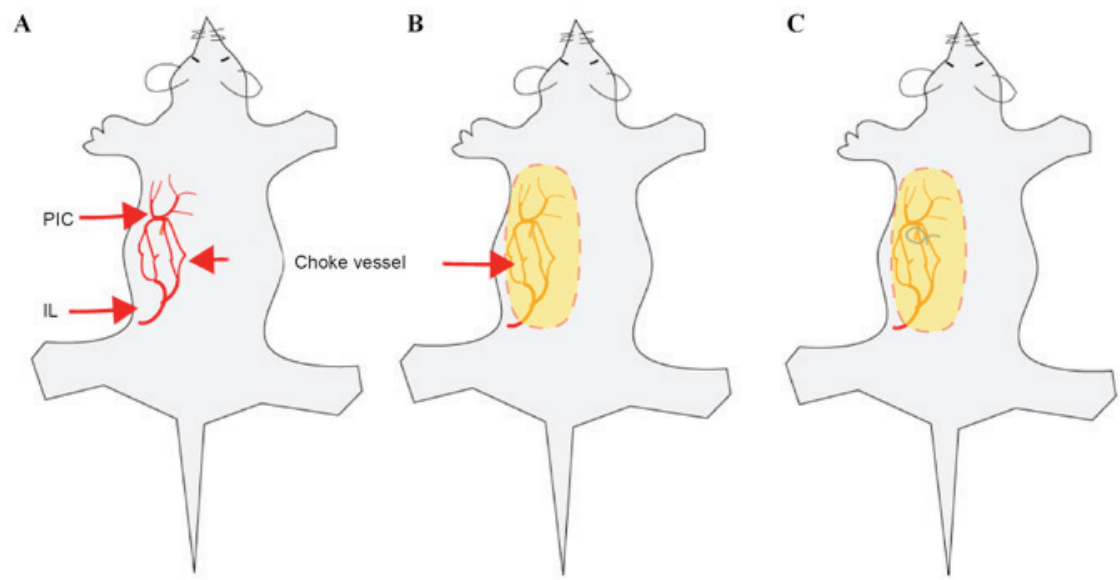

Figure 1. Schematic view of flap elevated. (A and B) Elevation of the flap based on two perforating arteries on the rat dorsum in all groups (red arrows indicate the choke vessels). (C) The final form of an extended flap was perfused via the iliolumbar vessel pedicle after ligation of the posterior intercostal vessel. PIC, posterior intercostal vessel; IL, iliolumbar vessel.
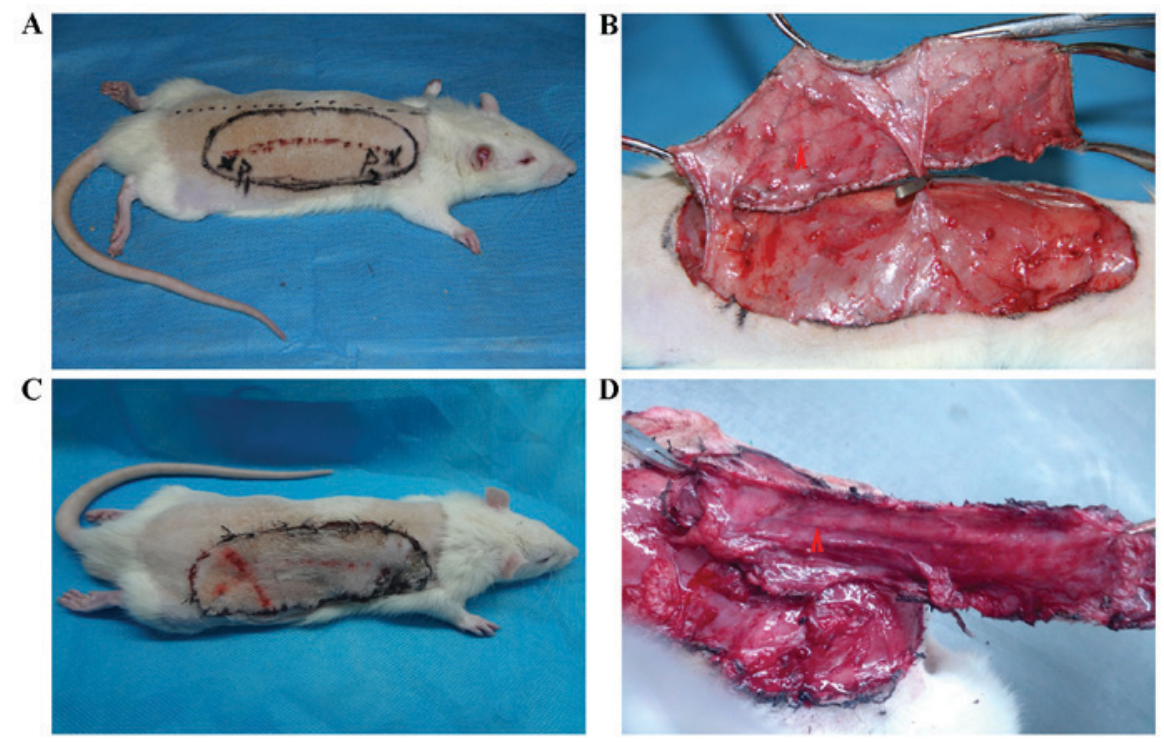

Figure 2. Flap elevation: (A) Design of the flap based on two vascular regions. (B) Interoperative view of the flap; the choke vessels were small-caliber or not opened (red arrow). The posterior intercostal vessel was ligated. (C) Postoperative view of the closed flap at day 7. (D) Choke vessels were dilated at day 7 (red arrow).

Total RNA extraction and reverse-transcription quantitative polymerase chain reaction ( $R T-q P C R)$. RT-qPCR analysis was performed to examine the expression of MCP-1 and TNF- $\alpha$. Total RNA was isolated from skin flap tissues using TRIzol reagent (Invitrogen; Thermo Fisher Scientific, Inc., Waltham, MA, USA) and DNA was removed using DNase I (Invitrogen; Thermo Fisher Scientific, Inc.). These RNA samples were then reverse-transcribed into single-stranded complementary (c) DNA using the first-strand cDNA synthesis kit (Fermentas, Vilnius, Lithuania). These cDNA products were further amplified using qPCR by using the SYBR-Green RT-PCR kit (Bioteke, Beijing, China). The primers were from Invitrogen (Thermo Fisher Scientific, Inc.). Amplification was performed with a real-time qPCR machine (Stratagene, La Jolla, CA, USA). GAPDH was used as an internal control. The sequences of the PCR primers used in this study are listed in Table I. Relative expression of PCR products was determined using the $\Delta \Delta$ Cq method (22) with normalization to GAPDH mRNA expression.
Table I. Primer sequences used for reverse transcription-quantitative polymerase chain reaction.

\begin{tabular}{ll}
\hline Primer name & \multicolumn{1}{c}{ Primer sequence } \\
\hline GADPH & F: 5'-TGCCCCATGTTTGTGATG-3' \\
GADPH & R: 5'-TTACGTAGGACGTGGTGGT-3' \\
TNF- $\alpha$ & F: 5'-CCAGGAGAAAGTCAGCCTCCT-3' \\
TNF- $\alpha$ & R: 5'-TCATACCAGGGCTTGAGCTCA-3' \\
MCP-1 & F: 5'-AGCACCTTTGAATGTGAACT-3' \\
MCP-1 & R: 5'-AGAAGTGCTTGAGGTGGTT-3'
\end{tabular}

F, forward; R, reverse; MCP, Monocyte chemoattractant protein-1; TNF, tumor necrosis factor.

Statistical analysis. SPSS version 17.0 for Windows (SPSS Inc., Chicago, IL, USA) was used for data management and 


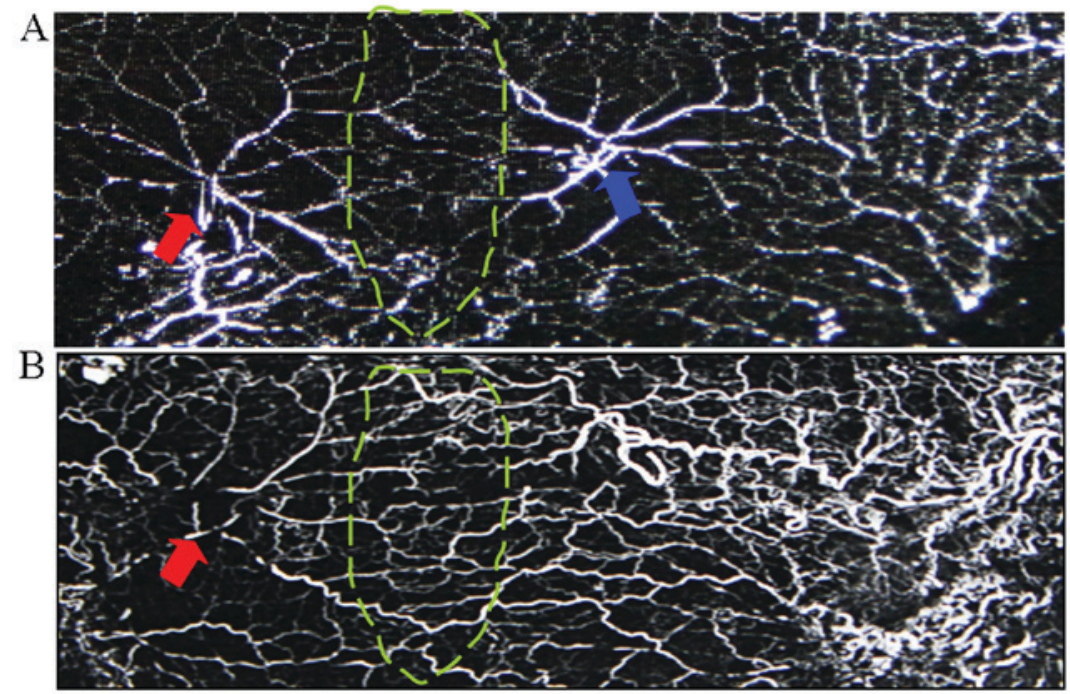

Figure 3. Radiography images of choke vessels in surgical flaps of injected with a lead oxide and gelatin compound. (A) Control group (Blue arrow: posterior intercostal vessel); (B) The choke arterioles (within green dashed lines) indicated dilation and tortuous paths at 7 days post operation. The iliolumbar artery (red arrow) had increased its territory to supply adjacent vascular territories.
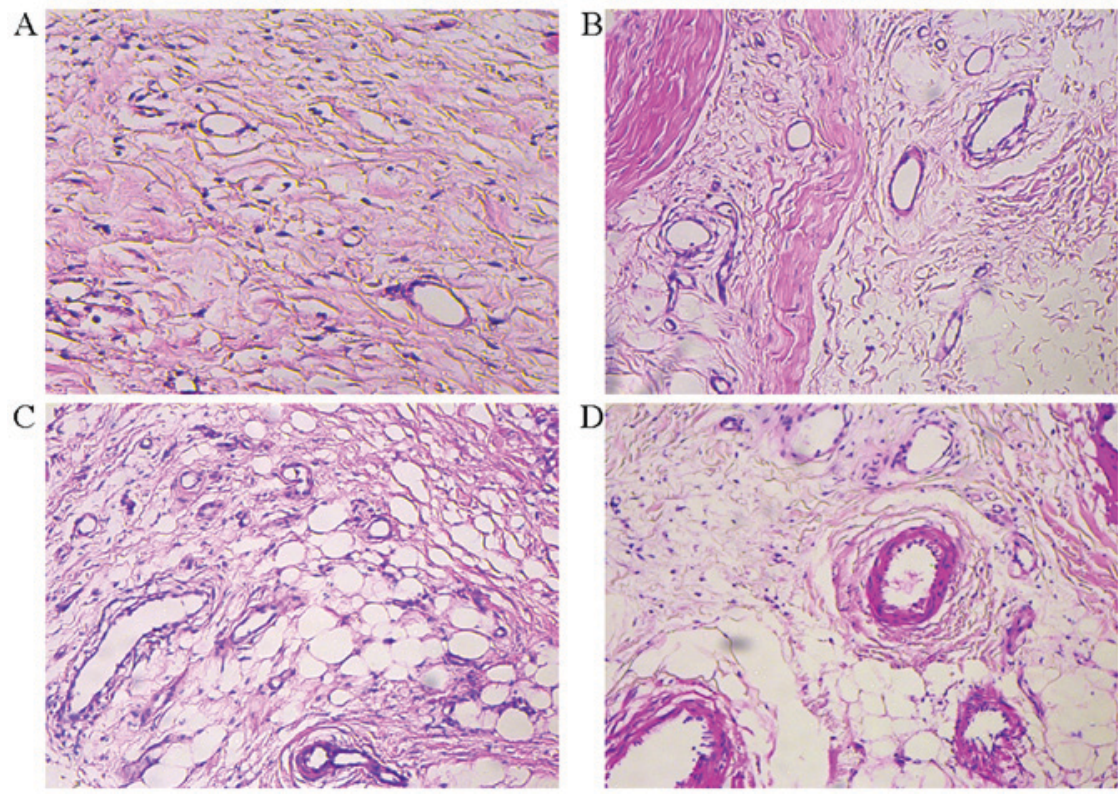

Figure 4. (A) Histopathological examination of the first choke zone in the surgical flaps showed that the degree of inflammatory cell infiltration and interstitial edema was not obvious in the control group. (B) In the experimental group, tissue clearance showed edema, inflammatory cell aggregation and vessel dilation at 3 days post operation. (C and D) The dilation of choke vessel caliber and increasing vessel wall thickness was clear up to 7 days following flap elevation (C) Results at 5 days (D) results at 7 days. Samples were stained with hematoxylin and eosin. (magnification, x100).

statistical analysis. Values are expressed as the mean \pm standard error of the mean. Statistical analyses were performed using one-way analysis of variance followed by post-hoc multiple comparisons. $\mathrm{P}<0.05$ was considered to indicate a statistically significant difference between values.

\section{Results}

Choke vessel remodeling of flap post operation. At 7 days post operation, the choke vessels at the choke zone were clearly dilated. Arteriography showed that choke vessels showed dilation and tortuous paths, and that the iliolumbar artery had increased its territory to supply adjacent vascular territories (Fig. 3).
Histopathological changes in flap post operation. Histopathological changes of flaps were seen between the groups. No marked inflammation was present in the control group. However, in the experimental group, clearances in the tissues indicated edema, and inflammatory cell infiltration as well as vessel dilation were present at 3 days post operation. Dilation of the choke vessels and increasing vessel wall thickness were obvious over the following days until 7 days (Fig. 4). These results indicated that inflammation was involved in choke vessel remodeling.

Inflammatory response-associated biomarker levels in the flap. To assess the effects of inflammatory factors on choke 

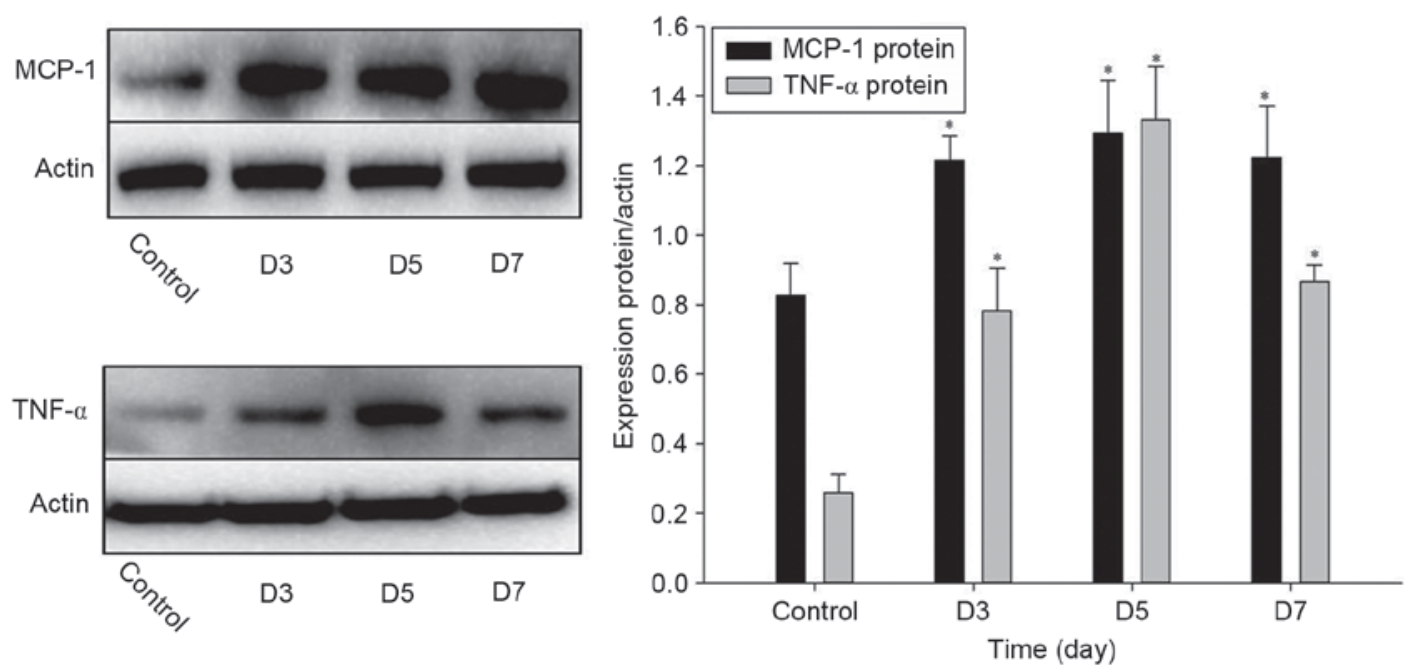

Figure 5. Compared with those in the control group, the levels of MCP-1 and TNF- $\alpha$ protein in the choke zone were significantly elevated at day 3 after flap elevation and reached a maximum at day 5 . There were no significant differences between days 5 and 7 in MCP-1 levels, while TNF- $\alpha$ levels significantly decreased at day 7 compared with day $5(\mathrm{P}=0.003)$. ${ }^{*} \mathrm{P}<0.001$. vs. Control. $\mathrm{MCP}$, monocyte chemoattractant protein; $\mathrm{TNF}$, tumor necrosis factor.

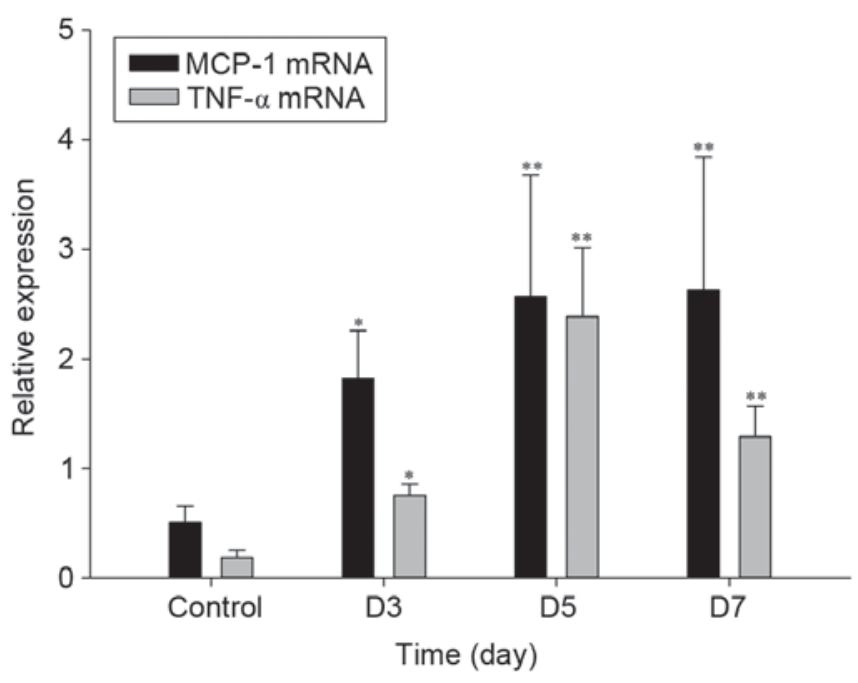

Figure 6. Reverse-transcription quantitative polymerase chain reaction was used to examine the gene expression of MCP-1 and TNF- $\alpha$ in the choke zone The mRNA levels of MCP-1 and TNF- $\alpha$ steadily increased at 3 and 5 days post operation. There were no significant differences between days 5 and 7 for the MCP-1, while the level of TNF- $\alpha$ significantly decreased at day 7 compared with day $5(\mathrm{P}=0.034) .{ }^{*} \mathrm{P}<0.05,{ }^{* *} \mathrm{P}<0.01$ vs. Control. MCP, monocyte chemoattractant protein; TNF, tumor necrosis factor.

vessel remodeling, a fraction of the flap was excised from the choke zone and the expression levels of MCP-1 and TNF- $\alpha$ as inflammatory markers were examined by using RT-qPCR and western blot analysis. As indicated in Fig. 5, western blot analysis revealed changes in the protein expression of MCP-1 and TNF- $\alpha$ in the flap choke zone at various time-points after operation. The protein levels of MCP-1 and TNF- $\alpha$ were significantly elevated at 3 and 5 days after operation, and had slightly declined at 7 days (Fig. 5). Similarly, the mRNA expression of MCP-1 and TNF- $\alpha$ were also significantly upregulated at 3-7 days after the operation with a maximum at 5 days (Fig. 6). These results suggested that these two inflammatory factors were involved in inflammation in the flap.

\section{Discussion}

Ischemic necrosis of the surgical skin flap is a common complication and may result in significant cosmetic and functional defects (23). Vascular supply to the integument is crucial for the survival of surgical perforator flaps. Angiosomes are the areas of skin perfused by blood vessels (24). Adjacent angiosomes are linked through choke vessels. When blood flow to angiosomes is disrupted, adjacent angiosomes can expand via choke vessel remodeling to compensate for the decreased blood flow $(25,26)$. In the present study, histopathological analysis and arteriography showed that the dilation of the choke vessel caliber and increasing vessel wall thickness was obvious at 7 days post operation. The iliolumbar artery had increased its territory to supply adjacent vascular territories.

Choke vessel remodeling occurs via the process of arteriogenesis (27), which is the sprouting of microvessels from a preexisting capillary network. It requires an inflammatory environment and numerous cytokines are commonly involved in general inflammatory responses and arteriogenesis. The inflammatory response has been considered as the major factor involved in neovascularization and vascular remodeling (26). To determine whether inflammatory responses are involved in postoperative choke vessel remodeling, MCP-1 and TNF- $\alpha$ were examined in the present study as an inflammatory cytokines in the choke zone. The results showed that the expression levels of TNF- $\alpha$ and MCP- 1 in the choke zone were obviously increased in tissues showing postoperative choke vessel growth. The results of the present study confirmed the hypothesis that the inflammatory response may have an important role in choke vessels remodeling. This result was similar to that of a study by Williams et al (26), which supported that ischemia may not have a role in choke-vessel changes, whereas an inflammatory environment was shown to be involved in the growth of choke vessels.

In the present study, TNF- $\alpha$ increased at day 3 after flap elevation and was further increased at day 5 , while showing a decline at day 7. MCP-1 increased at day 3 after flap elevation, reached a maximum at day 5 and then plateaued. It is 
commonly accepted that hypoxia/ischemia is involved in the extended perforator flap prior to choke vessel remodeling $(7,9)$ TNF- $\alpha$ is well known to be involved in the inflammatory response elicited in regions of cerebral ischemia. Subsequent to an ischemic insult, the levels of TNF- $\alpha$ may indeed remain elevated in the affected brain tissue for at least $24 \mathrm{~h}$ (28). TNF- $\alpha$ mediates remodeling and repair through activating collagen formation and matrix metalloproteinases, and regulates integrins, progenitor cell mobilization and angiogenesis (21). MCP-1 also has an important role in ischemia-induced angiogenesis by promoting early inflammatory mononuclear cell infiltration $(13,29)$. MCP-1 was found to be upregulated in the venular endothelium of ischemic myocardial segments (18). Transforming growth factor (TGF)- $\beta 1$ was reported to significantly contribute to this chemotactic activity, and monocyte chemotactic activity in lymph was largely dependent on the concerted action of MCP-1 and TGF- $\beta 1$ (30).

After establishment of the extended perforator flap model, the blood flow through the choke vessels may be elevated $(7,9)$. Physical forces generated within the collateral arterioles after an increase of blood flow trigger vessel growth. Increases in physical forces stimulate the production of chemokines and chemokine receptors. Chemokines regulate the accumulation of leukocytes at inflammatory sites (10). MCP-1 is one of the key chemokines that regulate migration and infiltration of monocytes/macrophages (31). Macrophages are important in the induction of new blood vessel growth during wound repair, tumor growth and inflammation. In the present study, histological analysis revealed edema and inflammatory cell aggregation at 3,5 and 7 days post operation. Several studies also suggested that TNF- $\alpha$ is responsible for macrophage-derived angiogenic activity $(11,17,32)$. The angiogenic activity produced by activated murine macrophages was reported to be neutralized by a polyclonal antibody to TNF- $\alpha$. Although it has been illustrated that TNF- $\alpha$ induces capillary blood vessel formation during tumor development in inflammation and wound repair, TNF- $\alpha$ also augmented repair by stimulating the growth of new blood vessels $(15,33)$. In the present study, the mRNA levels of the inflammatory markers showed obvious changes in flap tissues with postoperative choke vessel growth. The mRNA levels of MCP-1 and TNF- $\alpha$ were upregulated post operation. These results showed that MCP-1 and TNF- $\alpha$ are potent inducers of choke vessel remodeling.

In conclusion, the findings of the present study indicated that the inflammatory response may have an important role in choke vessel remodeling. Furthermore, molecular evidence of the involvement of an inflammatory environment in vessel development in the choke zone was provided. MCP-1 and TNF- $\alpha$ may become possible target molecules to modulate the behavior of choke vessels.

\section{References}

1. Tang J, Fang T, Song D, Liang J, Yu F and Wang C: Free deep inferior epigastric artery perforator flap for reconstruction of soft-tissue defects in extremities of children. Microsurgery 11: 22127, 2013.

2. Zeltzer AA and Van Landuyt K: Reconstruction of a massive lower limb soft-tissue defect by giant free DIEAP flap. J Plast Reconstr Aesthet Surg 65: e42-e45, 2012.

3. Gill PS, Hunt JP, Guerra AB, Dellacroce FJ, Sullivan SK, Boraski J, Metzinger SE, Dupin CL and Allen RJ: A 10-year retrospective review of 758 DIEP flaps for breast reconstruction. Plast Reconstr Surg 113: 1153-1160, 2004.
4. Taylor GI, Chubb DP and Ashton MW: True and 'choke' anastomoses between perforator angiosomes: Part i. anatomical location. Plast Reconstr Surg 132: 1447-1456, 2013.

5. Chubb DP, Taylor GI and Ashton MW: True and 'choke' anastomoses between perforator angiosomes: Part II. dynamic thermographic identification. Plast Reconstr Surg 132: 1457-1464, 2013.

6. Taylor GI and Pan WR: Angiosomes of the leg: Anatomic study and clinical implications. Plast Reconstr Surg 102: 599-618, 1998.

7. Miyamoto S, Minabe T and Harii K: Effect of recipient arterial blood inflow on free flap survival area. Plast Reconstr Surg 121: 505-513, 2008.

8. Zhuang Y, Hu S, Wu D, Tang M and Xu da C: A novel in vivo technique for observations of choke vessels in a rat skin flap model. Plast Reconstr Surg 130: 308-317, 2012.

9. Dhar SC and Taylor GI: The delay phenomenon: The story unfolds. Plast Reconstr Surg 104: 2079-2091, 1999.

10. Smits AI, Ballotta V, Driessen-Mol A, Bouten CV and Baaijens FP: Shear flow affects selective monocyte recruitment into MCP-1-loaded scaffolds. J Cell Mol Med 18: 2176-2188, 2014.

11. Cochain C, Channon KM and Silvestre JS: Angiogenesis in the infarcted myocardium. Antioxid Redox Signal 18: 1100-1113, 2013.

12. Szabó $\mathrm{C}$ and Papapetropoulos A: Hydrogen sulphide and angiogenesis: Mechanisms and applications. Br J Pharmacol 164: 853-865, 2011.

13. Matsui H, Motooka M, Koike H, Inoue M, Iwasaki T, Suzuki T, Kurabayashi $\mathrm{M}$ and Yokoyama T: Ischemia/reperfusion in rat heart induces leptin and leptin receptor gene expression. Life Sci 80: 672-680, 2007.

14. Chalothorn D, Clayton JA, Zhang H, Pomp D and Faber JE: Collateral density, remodeling, and VEGF-A expression differ widely between mouse strains. Physiol Genomics 30: 179-191, 2007.

15. Yoshida S, Yoshida A and Ishibashi T: Induction of IL-8, MCP-1, and bFGF by TNF-alpha in retinal glial cells: Implications for retinal neovascularization during post-ischemic inflammation. Graefes Arch Clin Exp Ophthalmol 242: 409-413, 2004.

16. Frangogiannis NG, Smith CW and Entman ML: The inflammatory response in myocardial infarction. Cardiovasc Res 53: 31-47, 2002.

17. Wang L, Chopp M, Teng H, Bolz M, Francisco MA, Aluigi DM, Wang XL, Zhang RL, Chrsitensen S, Sager TN, et al: Tumor necrosis factor a primes cerebral endothelial cells for erythropoietin-induced angiogenesis. J Cereb Blood Flow Metab 31: 640-647, 2011.

18. Deshmane SL, Kremlev S, Amini S and Sawaya BE: Monocyte chemoattractant protein-1 (MCP-1): An overview. J Interferon Cytokine Res 29: 313-326, 2009.

19. Stowe AM, Wacker BK, Cravens PD, Perfater JL, Li MK, Hu R, Freie AB, Stüve O and Gidday JM: CCL2 upregulation triggers hypoxic preconditioning-induced protection from stroke. J Neuroinflammation 9: 33, 2012.

20. Roberts TK, Eugenin EA, Lopez L, Romero IA, Weksler BB, Couraud PO and Berman JW: CCL2 disrupts the adherens junction: Implications for neuroinflammation. Lab Invest 92: 1213-1233, 2012.

21. Vinores SA, Xiao WH, Shen J and Campochiaro PA: TNF-alpha is critical for ischemia-induced leukostasis, but not retinal neovascularization nor VEGF-induced leakage. J Neuroimmunol 182: 73-79, 2007.

22. Livak KJ and Schmittgen TD: Analysis of relative gene expression data using real-time quantitative PCR and the 2(-Delta Delta C(T)) Method. Methods 25: 402-408, 2001.

23. Sun Y, Li QF, Zhang Y, Hu R and Jiang H: Isoflurane preconditioning increases survival of rat skin random-pattern flaps by induction of HIF-1alpha expression. Cell Physiol Biochem 31: 579-591, 2013.

24. Hamilton K, Wolfswinkel EM, Weathers WM, Xue AS, Hatef DA, Izaddoost S and Hollier LH Jr: The delay phenomenon: A compilation of knowledge across specialties. Craniomaxillofac Trauma Reconstr 7: 112-118, 2014.

25. Gigliofiorito P, Iacob S, Pendolino AL, Piombino L, Segreto F and Persichetti P: True and 'choke' anastomoses between perforator angiosomes: Part I. Anatomical location. Plast Reconstr Surg 133: 890e-891e, 2014.

26. Williams BA, Currie RW and Morris SF: Impact of arteriogenesis in plastic surgery: Choke vessel growth proceeds via arteriogenic mechanisms in the rat dorsal island skin flap. Microcirculation 16: 235-250, 2009. 
27. Ghali S, Butler PE, Tepper OM and Gurtner GC: Vascular delay revisited. Plast Reconstr Surg 119: 1735-1744, 2007.

28. Goukassian DA, Qin G, Dolan C, Murayama T, Silver M, Curry C, Eaton E, Luedemann C, Ma H, Asahara T, et al: Tumor necrosis factor-alpha receptor $\mathrm{p} 75$ is required in ischemia-induced neovascularization. Circulation 115: 752-762, 2007.

29. Stevens CR, Williams RB, Farrell AJ and Blake DR: Hypoxia and inflammatory synovitis: Observations and speculation. Ann Rheum Dis 50: 124-132, 1991.

30. Bouchentouf M, Paradis P, Forner KA, Cuerquis J, Boivin MN Zheng J, Boulassel MR, Routy JP, Schiffrin EL and Galipeau J: Monocyte derivatives promote angiogenesis and myocyte survival in a model of myocardial infarction. Cell Transplant 19: 369-386, 2010.

31. Rangasamy S, McGuire PG, Franco Nitta C, Monickaraj F, Oruganti SR and Das A: Chemokine mediated monocyte trafficking into the retina: Role of inflammation in alteration of the blood-retinal barrier in diabetic retinopathy. PLoS One 9: e108508, 2014
32. Kwon YW, Heo SC, Jeong GO, Yoon JW, Mo WM, Lee MJ, Jang IH, Kwon SM, Lee JS and Kim JH: Tumor necrosis factor-a-activated mesenchymal stem cells promote endothelial progenitor cell homing and angiogenesis. Biochim Biophys Acta 1832: 2136-2144, 2013.

33. Gardiner TA, Gibson DS, de Gooyer TE, de la Cruz VF, McDonald DM and Stitt AW: Inhibition of tumor necrosis factor-alpha improves physiological angiogenesis and reduces pathological neovascularization in ischemic retinopathy. Am J Pathol 166: 637-644, 2005. 